\title{
MAHASISWA BERCADAR DAN GERAKAN SOSIAL (KAJIAN TENTANG PERSPEKTIF DAN PARTISIPASI MAHASISWA BERCADAR TERHADAP GERAKAN SOSIAL UNIVERSITAS NEGERI MAKASSAR)
}

\author{
Arisnawawi $^{1 *}$, Ashari Ismail ${ }^{2}$ \\ ${ }^{1}$ Mahasiswa/Sosiologi \\ Universitas Negeri Makassar \\ Email: aris19n@gmail.com \\ ${ }^{2}$ Dosen/Sosiologi \\ Universitas Negeri Makassar \\ Email:
}

\begin{abstract}
ABSTRAK
Mahasiswa bercadar menjadi salah satu representasi dari ajaran agama Islam. Agama ini memiliki beberapa perintah atau anjuran. Diantaranya membantu orang yang tertindas atau terzalimi. Anjuran agama in,i memiliki korelasi substansial dengan tujuan gerakan sosial aksi demonstrasi mahasiswa UNM. Yaitu untuk membantu rakyat yang tertindas atau terzalimi. Melihat keserasian antara anjuran agama dan tujuan gerakan sosial demontrasi, namun pada kenyataannya jarang atau bahkan tidak pernah terlihat mahasiswa bercadar UNM hadir dalam rentetan gerakan sosial aksi demonstrasi UNM. Penelitian ini bertujuan untuk mengetahui bagaimana perspektif mahasiswa bercadar UNM terhadap gerakan sosial aksi demonstrasi mahasiswa UNM serta bagaimana partisipasi mahasiswa bercadar UNM dalam gerakan sosial secara umum. Penelitian ini menggunakan pendekatan kualitatif. Lokasi dan Informan penelitian berada di Universitas Negeri Makassar yang tersebar dalam berbagai fakultas. Penentuan informan dilakukan dengan purposive sampling yang melibatkan 20 individu sebagai informan. Teknik pengumpulan data dilakukan dengan observasi, wawancara, dan dokumentasi. Berdasarkan hasil penelitian dapat disimpulkan bahwa Perspektif mahasiswa bercadar UNM terhadap gerakan sosial aksi demonstrasi di UNM terdiri dari perspektif positif dan perspektif negatif. Bentuk partisipasi mahasiswa bercadar UNM dalam melakukan gerakan sosial dibagi menjadi dua bentuk. Yakni partisipasi dalam bentuk berwujud fisik atau nyata dan partisipasi dalam bentuk tidak berwujud fisik atau tidak nyata.
\end{abstract}

Kata kunci: mahasiswa bercadar dan gerakan sosial

\begin{abstract}
Veiled students are a representation of the teachings of Islam. This religion has several commands or recommendations. Among them help people who are oppressed or wronged. This religious suggestion has a substantial correlation with the aims of the social movement of the UNM student demonstrations. Namely to help people who are oppressed or oppressed. Seeing the harmony between religious advice and the goals of the social demonstration movement, in reality it is rare or even never seen that UNMveiled students are present in a series of UNM demonstration social movements. This study aims to find out how the perspective of UNM veiled students towards the social movement of UNM student demonstrations and how the participation of UNM veiled students in social movements in general. This research uses a qualitative approach.
\end{abstract}


Jurnal Predestination: jurnal of Society and Culture.

Vol .1 No.2, Maret 2021

Location and research informants are at Makassar State University, which are spread over various faculties. Determination of informants is done by purposive sampling involving 20 individuals as informants. The data collection technique was done by observing, interviewing and documenting. Based on the research results, it can be concluded that the perspective of UNM-veiled students towards the social movement of demonstrations at UNM consists of a positive perspective and a negative perspective. The form of participation of UNM veiled students in carrying out social movements is divided into two forms. Namely participation in physical or tangible form and participation in physical or intangible form.

\section{Keywords: Veiled Student and Social Movement}

\section{PENDAHULUAN}

Fenomena keagamaan yang menjadi banyak sorotan dalam masyarakat Indonesia salah satunya adalah penggunaan cadar oleh perempuan atau muslimah yang beragama Islam. Menurut M. Shalih (Muzakki, 2019 h. 29) cadar bukan hanya penutup wajah, melainkan jilbab yang tebal dan longgar, menutupi seluruh aurat termasuk wajah dan telapak tangan. Penampakan mahasiswa bercadar yang ada pada Perguruan Tinggi (PT) Universitas Negeri Makassar (UNM) sangat menarik perhatian. Bagaimana tidak, UNM tidak memiliki orientasi akademik yang menjurus khusus ke study agama. Khususnya agama Islam dan aqidah Islam.

Menurut Jati (2014 h. 138) bahwa kehadiran agama dalam kehidupan manusia, memiliki esensi mendasar untuk membebaskan manusia atas penderitaan. Sedang dari Misrawi (Riyadi, 2015 h.120) mengemukakan bahwa kehadiran agama tidak boleh hanya dipahami sebatas ritualisme belaka, namun harus dipahami pula sebagai bentuk pembebasan masyarakat dari segala penindasan. Pandangan dan ajaran agama islam yang menentang tindakan penindasan memiliki korelasi secara substansial atau kesamaan dalam pergerakan sosial kemahasiswaan. Salah satunya gerakan sosial demonstrasi. Gerakan sosial demonstrasi mahasiswa merupakan salah satu jalan untuk menolong dan membantu rakyat kecil, rakyat yang tertindas atau terzalimi yang tidak dapat melawan dan melepaskan diri dari jeratan penderitaan kaum penindas.

Mahasiswa tidak gentar menentang kebijakan yang tidak pro rakyat, berani menyatakan sikap, berani melakukan pengungkapan kebenaran. Alfatur (2019: 24) mengemukakan bahwa seorang mahasiswa memiliki kematangan dalam berpikir dan kecermatan dalam bertindak. Mahasiswa adalah manusia-manusia yang merdeka yang tidak bisa dibujuk oleh iming-iming apapun untuk menghianati kematangan berpikirnya. Dengan ini, guna mengaplikasikan tugas mahasiswa sebagai agen of change dan social of control, dapat dilakukan dengan berpartisipasi melawan penindasasan, ketidakadilan dalam upaya menolong orang lain melalui jalan gerakan sosial demonstrasi. Menurut Asiyah (2013 h. 109) bahwa tugas mahasiswa bukan sekedar belajar dalam teori namun krisis dalam praktik. Mahasiswa dituntut untuk peka terhadap permasalahan sosial yang tertuang dalam tridarma perguruan tinggi.

Blumer mengemukakan bahwa gerakan sosial merupakan "upaya kolektif untuk membangun tatanan kehidupan yang baru". Sedang Smelser menspesifikasikan gerakan sosial sebagai "upaya kolektif untuk mengubah norma dan nilai". Turner dan Killian sendiri menganggap gerakan sosial sebagai "tindakan kolektif berkelanjutan untuk mendorong dan menghambat perubahan dalam masyarakat atau dalam kelompok yang menjadi bagian masyarakat itu" (Sztompka, 2014: 325). Sehingga, gerakan sosial pada intinya adalah upaya untuk membantu, yang pada akhirnya akan mendapatkan perubahan 
Jurnal Predestination: jurnal of Society and Culture.

Vol .1 No.2, Maret 2021

yang lebih baik. Gerakan sosial demonstrasi adalah salah satu jembatan untuk saling bantu-membantu dan tolong-menolong.

Salah satu kelompok mahasiswa dalam Perguruan Tinggi yang sering menggelar gerakan sosial dengan cara demonstrasi di wilayah Indonesia Timur adalah mahasiswa UNM. Hal ini dilakukan guna membantu membebaskan manusia dari belenggu penderitaan akibat penindasan. Jika agama Islam menganjurkan untuk saling membantu, tidak menghendaki perbuatan penindasan/eksploitasi, maka sudah menjadi tugas seorang muslim dan muslimah untuk menolong. Dalam dunia mahasiswa, gerakan sosial demonstrasi merupakan salah satu wadah untuk mahasiswa muslim dan muslimah berpartisipasi dalam membantu masyarakat yang tertindas. Hal yang menjadi banyak sorotan publik dalam gerakan sosial demontrasi mahasiswa UNM adalah adanya kelompok mahasiswa atau individu yang terindentifikasi tidak pernah bergabung dalam gerakan sosial ini, yakni mahasiswa bercadar.

Mengapa gerakan sosial dengan cara demonstrasi tidak pernah diikuti oleh mahasiswa atau muslimah bercadar. Sedangkan mereka bagian representasi penganut agama Islam yang taat. Penelitian ini ingin memahami dua rumusan masalah, diantaranya: 1) Bagaimana perspektif mahasiswa bercadar Universitas Negeri Makassar terhadap gerakan sosial aksi demonstrasi mahasiswa Universitas Negeri Makassar? 2) Bagaimana bentuk partisipasi mahasiswa bercadar Universitas Negeri Makassar dalam gerakan sosial?

\section{METODE}

Jenis penelitian yang digunakan dalam penelitian ini adalah penelitian kualitatif dengan pendekatan deskriptif. Pendekatan deskriptif dalam penelitian ini bertujuan untuk menggambarkan secara sistematis dan akurat mengenai fakta-fakta gerakan sosial.. Penelitian ini dilakukan untuk mendapatkan gambaran kusus mengenai "perspektif dan partisipasi mahasiswa bercadar UNM dalam gerakan sosial Universitas Negeri Makassar". lokasi penelitian berada di Universitas Negeri Makassar. Teknik pengumpulan data yang digunakan adalah observasi, wawancara, dan dokumentasi. Dengan menggunakan teknik purposive sampling ialah teknik memilih sampel dan data dengan pertimbangan tertentu sesuai kriteria penelitian

\section{HASIL DAN PEMBAHASAN}

Penelitian ini menggunakan teori Tindakan Sosial. Konsep utamanya adalah tindakan rasional dan tindakan nonrasional. Dalam kategori tindakan rasional dan nonrasional, terdapat dua bagian yang berbeda satu sama lain. Weber (Johnson 1986, h. 220) mengklasifikasin tipe tindakan sosial menjadi empat yang memiliki pengaruh terhadap sistem dan struktur masyarakat, diantaranya

a. Rasional Instrumental

Rasional instrumental merupakan suatu tindakan yang menimbang dan memperhitungkan secara sadar dengan tujuan tindakan itu. Setiap individu memiliki bermacam-macam tujuan dalam bertindak, untuk itu individu menilai alat yang harus dipakai.

b. Rasional Beriorentasi Nilai

Rasionalitas beriorentasi nilai merupakan pertimbangan dan perhitungan yang sadar yakni dimana tujuanya sudah ada dalam hubungannya dengan nilai-nilai individu yang bersifat absolut.

c. Tindakan Tradisional

Tindakan tradisional merupakan tindakan nonrasional, dimana individu melakukan tindakan dikarenakan oleh kebiasaan tanpa refleksi kesadaran. 
Jurnal Predestination: jurnal of Society and Culture.

Vol .1 No.2, Maret 2021

Tindakan ini tidak terencana melalui proses penalaran, melainkan kebiasaankebiasaan yang ia dapatkan dari masa lalu.

d. Tindakan Afektif

Tindakan afektif merupakan tindakan non rasional, dimana tindakan didominasi oleh pengaruh perasaan

\section{Bagaimana perspektif mahasiswa bercadar Universitas Negeri Makassar terhadap gerakan sosial aksi demonstrasi mahasiswa Universitas Negeri Makassar?}

Perspektif mahasiswa bercadar terhadap gerakan sosial demontrasi terbagi menjadi dua, diantaranya

a. Perspektif Positif

Beberapa yang menyebabkan perspektif positif mahasiswa bercadar dalam memandang gerakan sosial aksi demonstrasi mahasiswa adalah adanya niat yang baik dari mahasiswa untuk membantu orang lain. Berdasarkan hasil wawancara diketahui bahwa niat baik ini mencakup keinginan untuk menegakkan kebenaran dan keadilan ditengah masyarakat yang bermasalah, memperjuangkan hak-hak rakyat hingga hak-hak mahasiswa itu sendiri. Dalam kehidupan sosial yang tidak statis meniscayakan adanya ragam permasalahan sehingga ragam solusi juga harus dihadirkan, termasuk ragam cara yang dapat dilakukan dalam membantu orang lain seperti melakukan gerakan sosial aksi demonstrasi.

"Setuju-setuju aja sih kalau memang udah kayak apa yah, bener gitu loh kalau dia melakukan menyuarakan kebenaran gitu yah saya setuju-setuju aja gitu. Yang jelas sudah ada konfirmasinya kalau memang mereka turun gitu dalam rangka untuk menyuarakan kebenaran gitu" (Hasil wawancara dengan S, Mahasiswa Fakultas Psikologi, 4 Maret 2020)

Gerakan sosial aksi demonstrasi juga dipandang dapat dijadikan sebagai salah satu jalan untuk melakukan perubahan yang lebih baik. Karena kehidupan berjalan dinamis sebagaimana pemahaman Aguste Comte. Maka kehidupan ini harus diarahkan dan dikontrol untuk mencapai perubahan yang diharapkan. Hal ini sesuai dengan tugas dan tanggung jawab seorang mahasiswa sebagai agen of change dan Agen of control. Sehingga partisipasi mahasiswa dalam gerakan sosial aksi demonstrasi dapat menjadi bagian dari menjalankan tugas suci sebagai seorang mahasiswa. Perubahan ini tentu harus didasarkan pada prinsip pemahaman bahwa hari ini harus lebih baik dari hari kemarin dan hari yang akan datang harus lebih baik dari hari ini. Perspektif lain yakni mahasiswa dianggap memiliki jati diri untuk berpihak pada kebenaran dan gerakan sosial aksi demonstrasi adalah salah satu manifestasi dari keberpihakan pada kebenaran.

b. Perspektif Negatif

perspektif negatif mahasiswa bercadar terhadap gerakan sosial aksi demonstrasi mahasiswa umumnya memandang gerakan sosial ini sebagai tindakan yang anarkis. Gerakan massa seperti aksi demonstrasi sangat rentan terprovokasi sehingga mengakibatkan terjadinya tindakan brutal, seperti menutup akses masyarakat, merusak fasilitas umum dan tindakan yang merugikan banyak orang. Munculnya tindakan anarkis ini kemudian dipahami sebagai suatu penyimpangan dalam dunia pendidikan karena hanya dijadikan pelampiasan semata, bukan edukasi. Sedangkan gerakan sosial untuk membantu orang lain haruslah bersifat edukatif, dalam hal ini memberi contoh yang baik. 
Jurnal Predestination: jurnal of Society and Culture.

Vol .1 No.2, Maret 2021

Gerakan ini sangat beragam dalam dunia pendidikan, bukan malahan gerakan sosial aksi demonstrasi yang banyak meresahkan masyarakat umum dijadikan sebagai contoh.

"Karna itu sangat anarkis. Mahasiswa bisa saja menutup jalan yang seharusnya digunakan untuk masyarakat. Dalam benak saya mahasiswa yang melakukan demonstrasi juga suka menghancurkan dan membuat polusi yang menyebabkan resah masyarakat. Intinya mahasiswa yang melakukan demonstrasi tidak mendapatkan solusi melainkan mereka hanya melampiaskam untuk kepuasannya." (Hasil wawancara dengan U, Mahasiswa Fakultas Ilmu Pendidikan, 22 Maret 2020)

Perspektif negatif yang lain adalah memandang gerakan sosial aksi demonstrasi UNM sebagai tindakan yang membuang-buang waktu dan tenaga. Hal ini disebabkan karena kurangnya tanggapan atas aspirasi yang dilontarkan dalam ruang publik. Jikalaupun gerakan ini ditanggapi, hanya didominasi tanggapan buruk dari berbagai pihak. Tujuan pendidikan untuk mencerdaskan dengan cara aktif dalam perkuliahan di kampus, alih-alih menggunakan kesempatan itu untuk turun di jalan-jalan. Hal ini karena gerakan sosial aksi demonstrasi sering berlangsung dengan bertepatan waktu perkuliahan akademik sehingga satu diantaranya harus menjadi korban. Selain itu, karena titik kumpul dan titik aksi biasanya dilaksanakan di kampus sehingga mengganggu proses perkuliahan, ditambah dengan atribut bunyi-bunyian yang sangat menggaggu fokus dalam menerima materi perkuliahan. Alhasil waktu pembelajaran produktif di ruang kelas menjadi kurang produktif.

Selain pandangan bahwa gerakan sosial aksi demonstrasi UNM sering berujung anarkis dan hanya membuang-buang waktu, gerakan ini juga dipandang tidak sesuai dengan anjuran agama. Hal ini dikarenakan, gerakan ini tidak pernah dicontohkan oleh nabi dan sahabat ketika akan menyuarakan pendapat atau aspirasinya. Adanya campur baur antara laki-laki dan perempuan dalam melakukan gerakan sosial aksi demonstrasi, terjadi desak-desakan, tidak teratur, adanya beragam bentuk celaan-celaan, mengumbar aib-aib dari pemimpin dan umumnya sangat mudah terprovokasi menambah deretan perbuatan-perbuatan yang tidak sesuai dengan anjuran agama. Gerakan sosial ini dipandang memiliki lebih banyak mudaratnya daripada kebaikannya. Berbuat baik dengan jalan buruk, tetaplah perbuatan itu dihukumi sebagai perbuatan buruk.

\section{Bagaimana bentuk partisipasi mahasiswa bercadar Universitas Negeri Makassar dalam gerakan sosial?}

Seluruh informan mahasiswa bercadar UNM baik yang memiliki perspektif negatif atau yang memiliki perspektif positif terhadap gerakan sosial aksi demonstrasi UNM pada kenyatannya tidak pernah ikut serta bergabung ditengahtengah pergelaran aksi demonstrasi mahasiswa UNM. Hal ini karena mereka memandang ada bentuk gerakan sosial lain yang lebih baik dan lebih mudah untuk dilaksanakan. Dalam hal ini, gerakan sosial non demontrasi. Dari hasil penelitian dapat diketahui bahwa keseluruhan informan penelitian tergabung dalam kelompok, baik berupa komunitas, organisasi maupun lembaga yang digunakan untuk berpartipasi melakukan gerakan sosial membantu sesama. Sebagian melakukan gerakan sosial ini secara rutin dan berkala, sebagian yang lain melakukan gerakannya secara relatif atau sesuai dengan kondisi.

Partisipasi mahasiswa bercadar terhadap gerakan sosial terbagi menjadi dua bentuk, diantaranya: 
Jurnal Predestination: jurnal of Society and Culture.

Vol .1 No.2, Maret 2021

a. Berbentuk Nyata (berwujud fisik)

Partisipasi mahasiswa bercadar dalam bentuk nyata terdiri dari partisipasi dengan uang, harta benda dan tenaga. Mereka merasa tidak terbebani dengan berbagai donasi yang digelontorkan untuk membantu orang. Mereka menyebut partisipasinya sebagai sedeqah atau infak dalam agama.

"Alhamdulillah saya pernah, seperti memberikan alat-alat tulis, buku, dan Al-Quran" (Hasil wawancara dengan A, Mahasiswa Fakultas Ilmu Pendidikan, 23 Maret 2020).

Dari partisipasi dengan uang umumnya digunakan untuk membeli benda atau barang-barang sesuai dengan keperluan dan kebutuhan sasaran penerima bantuan. Partisipasi ini sangat membantu disamping karena uang menjadi alat pertukaran yang digunakan oleh semua orang. Dari partisipasi harta benda, sebagian donasi harta berupa benda-benda diuangkan atau dipertukarkan dengan uang yang kelak akan dibelanjakan sebagaimana mestinya. Sebagian harta benda adalah donasi yang sesuai dengan kebutuhan dan keperluan sasaran penerima bantuan. Donasi harta benda ini berupa pemberian sembako, pakaian layak pakai, alat tulis, Al-quran dan sebagainya. Sedangkan partisipasi mahasiswa bercadar UNM dengan tenaga, berupa keikutsertaan secara langsung dalam lapangan baik dalam pengumpulan donasi maupun dalam penyebaran bantuan kepada sasaran bantuan. Selain itu, sebagian dari mereka aktif telibat dalam pemberian edukasi dalam melakukan gerakan sosial ini seperti mengajar dan berdakwah.

b. Berbentuk Tidak Nyata (Tidak berwujud fisik)

Sedangkan partisipasi mahasiswa bercadar UNM dalam bentuk tidak berwujud fisik atau tidak nyata dalam gerakan sosial adalah sumbangsi gagasan atau ide-ide. Berupa konsep untuk pelaksanaan gerakan sosial ini. Seperti menentukan jenis bantuan, cara mendapatkan donasi dan sebagainya tidak terlepaskan dari diskusi yang apik sehingga diperoleh konsep yang terbaik diantara yang baik.

"Sementara ini kami masih menyusun konsep tentang Al Qur'an yang bisa juga dipelajari oleh para dosen...Jadi bukan hanya mahasiswa. Tapi kami masih berencana belum terealisasi" (Hasil wawancara dengan U, Mahasiswa Fakultas Ilmu Pendidikan, 22 Maret 2020).

Sama dengan manusia dan mahasiswa pada umumnya, mahasiswa bercadar juga aktif dalam pemberian konsep dalam kelompoknya. Umumnya mereka memberikan konsep atau gagasan yang syar'i atau tidak melanggar hukum agama dalam melakukan gerakan sosial. Beberapa diantaranya adalah gagasan pembuatan metode yang memudahkan dalam mempelajari Al-Quran, gagasan pemberian bantuan pakaian syar'i berupa jilbab dan sebagainya kepada perempuan muslim yang membutuhkan, pemberian edukasi keagamaan sebagai jalan dakwah, pemberian bantuan sebagai bentuk sedeqah atau infak, dan sebagainya.

\section{KESIMPULAN}

Melihat jawaban mahasiswa bercadar dalam memandang dan menanggapi gerakan sosial demonstrasi mahasiswa UNM, pada umumnya mereka memilih untuk tidak ikut karena pilihan rasionalnya. Lebih banyak mudharat daripada kebaikannya untuk perempuan. Mahasiswa bercadar memilih gerakan sosial berbeda atau non demonstrasi dalam upaya menolong dan membantu orang lain baik yang tertindas atau 
Jurnal Predestination: jurnal of Society and Culture.

Vol .1 No.2, Maret 2021

terzalimi maupun yang membutuhkan bantuan secara umum. Umumnya mereka berpartisipasi didasarkan pada kepentingan kemanusiaan, pembebasan atas penderitaan. Gerakan sosial non demonstrasi menjadi pilihan mahasiswa bercadar karena gerakan sosial ini dipandang tidak mengandung unsur anarkisme, berupa kekerasan fisik dan tidak meresahkan masyarakat.

\section{DAFTAR PUSTAKA}

Alfatur A. B. A. 2019. Interaksi Mahasiswa Bercadar Fakultas Ilmu Sosial Universitas Negeri Makassar. Makassar: Universitas Negeri Makassar.

Asiyah N. 2013. Pola Asuh Demokratis, Kepercayaan Diri dan Kemandirian Mahasiswa Baru. Juranal Psikologi Indonesia, 2(2), 108-121.

Jati W. R. 2014. Agama dan Politik: Teologi Pembebasan sebagai Arena Profetisasi Agama. Jurnal Walisongo, 22(1), 133-156.

Johnson R. M. Z. 1986. Teori Sosiologi Klasik dan Modern. Jakarta: Gramedia.

Muzakki A. M. 2019. Interaksi Sosial Mahasiswa Bercadar di Lingkungan Universitas Islam Negeri Sunan Ampel Surabaya Menurut Perspektif George Herbert Mead. Surabaya: Universitas Islam Negeri Sunan Ampel Surabaya.

Riyadi A. A. 2015. Model Pembelajaran Pendidikan Islam Emansipatoris. Jurnal Program Studi PGRA, 1(2), 117-127.

Sztompka P. 2014. Sosiologi Perubahan Sosial. Jakarta: Prenada. 